Article

\title{
Compared Phenolic Compound Contents of 22 Commercial Fruit and Vegetable Juices: Relationship to Ex-Vivo Vascular Reactivity and Potential In Vivo Projection
}

\author{
Alexis Matute ${ }^{1}$, Jessica Tabart ${ }^{1}$, Jean-Paul Cheramy-Bien ${ }^{2}$, Bernard Pirotte ${ }^{3}$, Claire Kevers ${ }^{1}$ (D, \\ Cyril Auger ${ }^{4}\left(\mathbb{D}\right.$, Valérie Schini-Kerth ${ }^{4}\left(\mathbb{D}\right.$, Jacques Dommes ${ }^{1}$, Jean-Olivier Defraigne ${ }^{2}$ and \\ Joël Pincemail ${ }^{2, *}$ \\ 1 Laboratory of Plant Molecular Biology and Biotechnology, UR InBios-Phytosystems, University of Liège, \\ Sart Tilman, 4000 Liège, Belgium; afmmatute@student.uliege.be (A.M.); jessica.tabart@alumni.uliege.be (J.T.); \\ c.kevers@uliege.be (C.K.); j.dommes@uliege.be (J.D.) \\ 2 Department of Cardiovascular Surgery, CREDEC and Plateform Nutrition Antioxydante et Santé, CHU and \\ University of Liège, Sart Tilman, 4000 Liège, Belgium; jp.cheramy-bien@chuliege.be (J.-P.C.-B.); \\ jo.defraigne@chuliege.be (J.-O.D.) \\ 3 Laboratory of Medicinal Chemistry, Center for Interdisciplinary Research on Medicines (CIRM), Sart Tilman, \\ 4000 Liege, Belgium; b.pirotte@uliege.be \\ 4 Laboratory of Biophotonic and Pharmacy, Faculty of Pharmacy, University of Strasbourg, \\ 67401 Illkirch, France; cyril.auger@unistra.fr (C.A.); valerie.schini-kerth@unistra.fr (V.S.-K.) \\ * Correspondence: j.pincemail@chuliege.be; Tel.: +32-47-483-8071; Fax: +32-43-667-164
}

Received: 17 December 2019; Accepted: 17 January 2020; Published: 22 January 2020

\begin{abstract}
The real impact of polyphenol-rich vegetable and fruit juice intake on cardiovascular health remains a matter of controversy. In the present study, rat aorta segments immersed in an organ bath $(\mathrm{OB})$ were used to explore whether the total polyphenol content and/or individual phenolic compound contents of 22 commercial vegetable $(n=3)$ and fruit juices [(citrus $(n=5)$, berries $(n=10)$, apple $(n=2)$, pineapple $(n=2)$ ] might be associated with vascular tone. Red juices (particularly blackcurrant) and lemon juice caused the most marked vasorelaxation, its amplitude being endothelium dependent or not according to the volume ratio of juice to initial $\mathrm{OB}$ solution $\left.\mathrm{V}_{\text {juice }} / \mathrm{V}_{\mathrm{OBS}}\right)$. At volume ratios $5 \%$ and $10 \%$, both the juice and OB total polyphenol for all juices and total anthocyanin contents for berry juices significantly correlated with aorta vasorelaxation intensity. This was not the case for total or individual flavonols (except kaempferol) or for total or individual flavanols (except epigallocatechin gallate). If one relates our measured concentrations of individual phenolic compounds in OB to what is known about their physiological concentrations, and given our evidenced correlations between compound concentrations and vasorelaxation intensity, kaempferol, epigallocatechin gallate and peonidin-3-O-glucoside seem to emerge as the interesting phenolic compounds likely to be responsible for the potent vasorelaxation observed with fruit juices, and more particularly blackcurrant ones. Clinical investigation is required, however, to confirm our observations.
\end{abstract}

Keywords: fruit and vegetable juices; phenolic compounds; vasorelaxation effect; rat aorta

\section{Introduction}

Long considered anecdotal, the role played by antioxidants, and particularly polyphenols, is now viewed as pivotal in human disease prevention [1-5]. According to their chemical structure, natural polyphenols can be divided into lignans, lignins, stilbenes, styrylpyrones, arylpyrones, coumarins, tannins, phenolic acids (i.e., benzoic and cinnamic acid derivatives), and flavonoids (i.e., flavonols, 
flavanones, flavones, flavanols or catechins, anthocyans, and isoflavones). Flavonoids are particularly abundant in fruits, vegetables, and plant-derived products such as fruit juices, dark chocolate, green tea, red wine, coffee, and olive oil. Zutphen's study [6] was the first to evidence, in an elderly Dutch population, a strong inverse correlation between flavonoid consumption and the risk of developing cardiovascular disease. Using a food frequency questionnaire and the Phenol-Explorer database, Mendoça et al. [7] recently described the same relationship in a prospective cohort of 17,064 Spanish middle-aged university graduates (the "Seguimiento Universidad de Navarra" or SUN study). After adjusting for potential confounders, participants with a higher flavonoid intake (fifth quintile) showed a $47 \%$ lower incidence of cardiovascular events than those in the lowest quintile.

Polyphenols exert various actions likely to explain their cardioprotective effect. They notably have platelet aggregation and anti-inflammatory properties as well as ability to increase the high density lipoprotein (HDL)/low density lipoprotein (LDL) cholesterol ratio. They can also act as direct free radical scavengers but only at the stomach level. Despite low oral bioavailability and rapid metabolism, polyphenols may, however, at cellular level produce-through moderate auto-oxidation-small amounts of reactive oxygen species (ROS), which induces an antioxidant adaptive response in cells through the activation of the Keap1/Nrf2/ARE pathway. This results to over-expression of genes coding for antioxidant enzymes (Antioxidant Response Element) [8]. The physiological mechanism most often put forward to explain cardiovascular protection due to polyphenols is their ability to regulate arterial blood pressure by maintaining or improving endothelial function $[9,10]$. Indeed, polyphenols can increase the bioavailability of nitric oxide (NO), which has potent vasodilator properties. Many papers have evidenced an inverse relationship between endothelial dysfunction, as evaluated on the basis of flow-mediated dilation (FMD), and the risk of developing cardiovascular disease [11-13]. In contrast, important meta-analyses have clearly shown that a Mediterranean diet [14] or regular consumption of fruits, vegetables, or plant-derived products (dark chocolate, green tea, olive oil) can improve endothelium function and hence reduce both systolic and diastolic arterial pressure [15].

The aim of the present study was to examine the ability of several popular phenolic-compound-containing fruit and vegetable juices to improve ex-vivo endothelial function. Another objective was to identify the most effective subclasses of polyphenols and to see more generally whether a vasodilator effect could be observed in the presence of polyphenols at physiological concentrations $(\mu \mathrm{M})[16]$.

\section{Materials and Methods}

\subsection{Materials}

The following reagents were purchased from Merck KGaA, Darmstadt, Germany: cyanidin-3-O-glucoside (CyG), catechin (C), picatechin (EC), epicatechin gallate (ECG), gallocatechin (GC), epigallocatechin (EGC), and epigallocatechin gallate (EGCG). Cyanidin-3-O-rutinoside (CyR), delpinidin-3-O-glucoside (DG), delphinidin-3-O-rutoside (DR), peonidin-3-O-glucoside (PG), malvidin-3-O-glucoside (MG), delphinidin (D), cyanidin (Cy), petunidin (Pet), pelargonidin (Pel), peonidin (Peo), malvidin (M), kaempferol, myricetin, and quercetin were obtained from Extrasynthese Lyon, France.

Further, twenty-two commercial juices were bought in Belgian, French and German supermarkets and classified as vegetable or fruit juices. These were: (1) Tomato (Carrefour), (2) Tomato (Biotta), (3) Carrot (Biotta), (4) Orange (Carrefour), (5) Pure Orange (Vitamont), (6) Lemon (Bonneterre), (7) Grapefruit (Carrefour), (8) Pure Grapefruit (Vitamont), (9) Grape (Materne), (10) Pure Grape (Vitamont), (11) Pomegranate (Biotta), (12) Blackcurrant (Biotta), (13) Blackcurrant (Natreen), (14) Blackcurrant (Jacoby bio), (15) Blackcurrant (Van Nahmen), (16) Blackcurrant (Schlör Nectar), (17) Blackcurrant (Gut and Gunstig), (18) Blackcurrant (Jacoby), (19) Pineapple (Carrefour), (20) Pineapple Juice (De Drie Wilgen), (21) Apple (Carrefour), and (22) Pure Apple (Vitamont) (Figure 2). All beverages were 100\% pure vegetable or fruit juices except the blackcurrant ones that were nectar. 


\subsection{Determination of Total Phenolic Content}

The total polyphenol content of each juice (TPC-J) was determined according to the Folin-Ciocalteu (F-C) method [17]. In a 96-well microplate, $20 \mu \mathrm{L}$ of an appropriate juice dilution or standard solution (0-50 mg/L gallic acid) was mixed with $100 \mu \mathrm{L}$ of $10 \% \mathrm{~F}-\mathrm{C}$ reagent. After a 3-min incubation, $80 \mu \mathrm{L} \mathrm{Na}{ }_{2} \mathrm{CO}_{3}$ solution (7.5\% weight/volume) was added. The plate was then incubated at $30{ }^{\circ} \mathrm{C}$ for $1 \mathrm{~h}$. The absorbance at $750 \mathrm{~nm}$ was measured with a microplate reader (Multiskan Ascent, Thermo Labsystems, Helsinki, Finland). Results are expressed in $\mu \mathrm{g}$ gallic acid equivalents/mL juice ( $\mu \mathrm{g}$ GAE/mL, GAE: gallic acid equivalents).

\subsection{Specific Flavonoid Contents}

Separation and measurement of flavonols and anthocyanins were done by Ultra-Performance Liquid Chromatography (UPLC, Waters Corporation, Milford, MA, USA), according to protocols previously described by us [18]. The total flavonol content, expressed in $\mu \mathrm{g} / \mathrm{mL}$, was the sum of the quercetin, myricetin, and kaempferol contents. The total anthocyanin content, expressed in $\mu \mathrm{g} / \mathrm{mL}$, was the sum of D, DG, DR, Cy, CyG, CyR, PG, M, MG, Pet, Pel, and P. For flavanols, we used an HSS T3 steel cartridge (Waters), $2.1 \mathrm{~mm} \times 100 \mathrm{~mm}$, filled with $1.8 \mu \mathrm{m}$ particles and kept at $40{ }^{\circ} \mathrm{C}$. The mobile phase (flow rate: $0.2 \mathrm{~mL} / \mathrm{min}$ ) consisted of water/acetonitrile/formic acid 91/4/5 (v/v/v) at time 0 and 75/20/5 after $4 \mathrm{~min}$, followed by a steady state for $2 \mathrm{~min}$. For GC, ECG, EGC, and EGCG, the absorbance was recorded at $280 \mathrm{~nm}$. C and EC were analyzed by fluorescence spectroscopy (recording at $310 \mathrm{~nm}$ after an excitation at $280 \mathrm{~nm}$ ). The total flavanol content, expressed in $\mu \mathrm{g} / \mathrm{mL}$, was the sum of C, EC, GC, ECG, EGC, and EGCG.

\subsection{Vascular Reactivity}

Six-week-old male Wistar rats were obtained from the Central Animal Facility of the University Hospital Center of Liège and handled as recommended by the Ethics Committee for Animal Use of the University of Liege, Belgium (file 857, accepted in 2016). After anesthesia (pentobarbital, $60 \mathrm{mg} / \mathrm{mL} / \mathrm{kg}$ ), the thoracic aorta was removed carefully, cleaned of adhering fat and connective tissue, and cut into rings (2-3 mm long). The rings were then mounted and immersed in a $20 \mathrm{~mL}$ organ bath solution (OBS) at $40^{\circ} \mathrm{C}$, consisting of Krebs liquid $(118 \mathrm{mM} \mathrm{NaCl}, 25 \mathrm{mM} \mathrm{NaHCO} 3,5.5 \mathrm{mM}$-glucose, $4.7 \mathrm{mM} \mathrm{KCl}, 1.18 \mathrm{mM} \mathrm{KH}_{2} \mathrm{PO}_{4}, 2.4 \mathrm{mM} \mathrm{MgSO}_{4}$, and $3.3 \mathrm{mM} \mathrm{CaCl}_{2}, \mathrm{pH} 7.8$ ) continuously bubbled with $95 \% \mathrm{O}_{2}$ and $5 \% \mathrm{CO}_{2}$. The rings were equilibrated for $2 \mathrm{~h}$ before initiating the experimental protocols. To test the reactivity of the endothelium, contraction was induced with $\mathrm{KCl}(80 \mathrm{mM})$. When contraction reached a plateau, the $\mathrm{OB}$ chamber was washed thrice with Krebs solution. The functional endothelium was then tested by adding first $0.5 \%$ noradrenaline (to $0.1 \mu \mathrm{M}$ ), to induce contraction, and then acetylcholine (to $10 \mu \mathrm{M}$ ), to induce at least $80 \%$ vasorelaxation. After equilibration, the rings were contracted with phenylephrine $(0.5 \mu \mathrm{M})$ until contraction reached a plateau. Cumulative volumes of a fruit or vegetable juice $\left(\mathrm{V}_{\text {juice}}\right)$ were then added in OBS ( $\left.\mathrm{V}_{\mathrm{OBS}}\right)$ to reach a final volume of $2000 \mu \mathrm{L}$ $\left(\mathrm{V}_{\text {juice }} / \mathrm{V}_{\mathrm{OBS}} 10 \%\right.$ ) over a period of $1 \mathrm{~h}$ and a concentration-relaxation curve was constructed. Three to four independent assays were run for each concentration. Figure 1 depicts typical vasorelaxation graphs obtained with juices 1 and 18 (Tomato Carrefour and Blackcurrant Jacoby). Four-parameter sigmoidal dose-response curves were fitted to the data with GraphPad Prism (version 6.0, GraphPad Software, Inc., San Diego, CA, USA). $\mathrm{E}^{+}$represents the mean percentage of vasorelaxation determined at three different ratios (expressed as percentages) of juice volume to initial volume of OB solution ( $\mathrm{V}_{\text {juice }} / \mathrm{V}_{\mathrm{OBS}}$ ratios): $1 \%, 5 \%$, and $10 \%$. Relaxation of $100 \%$ was considered as high interest. The whole protocol was then repeated after careful removal of the endothelium to determine vasorelaxation in absence of endothelium $\left(\mathrm{E}^{-}\right)$. 


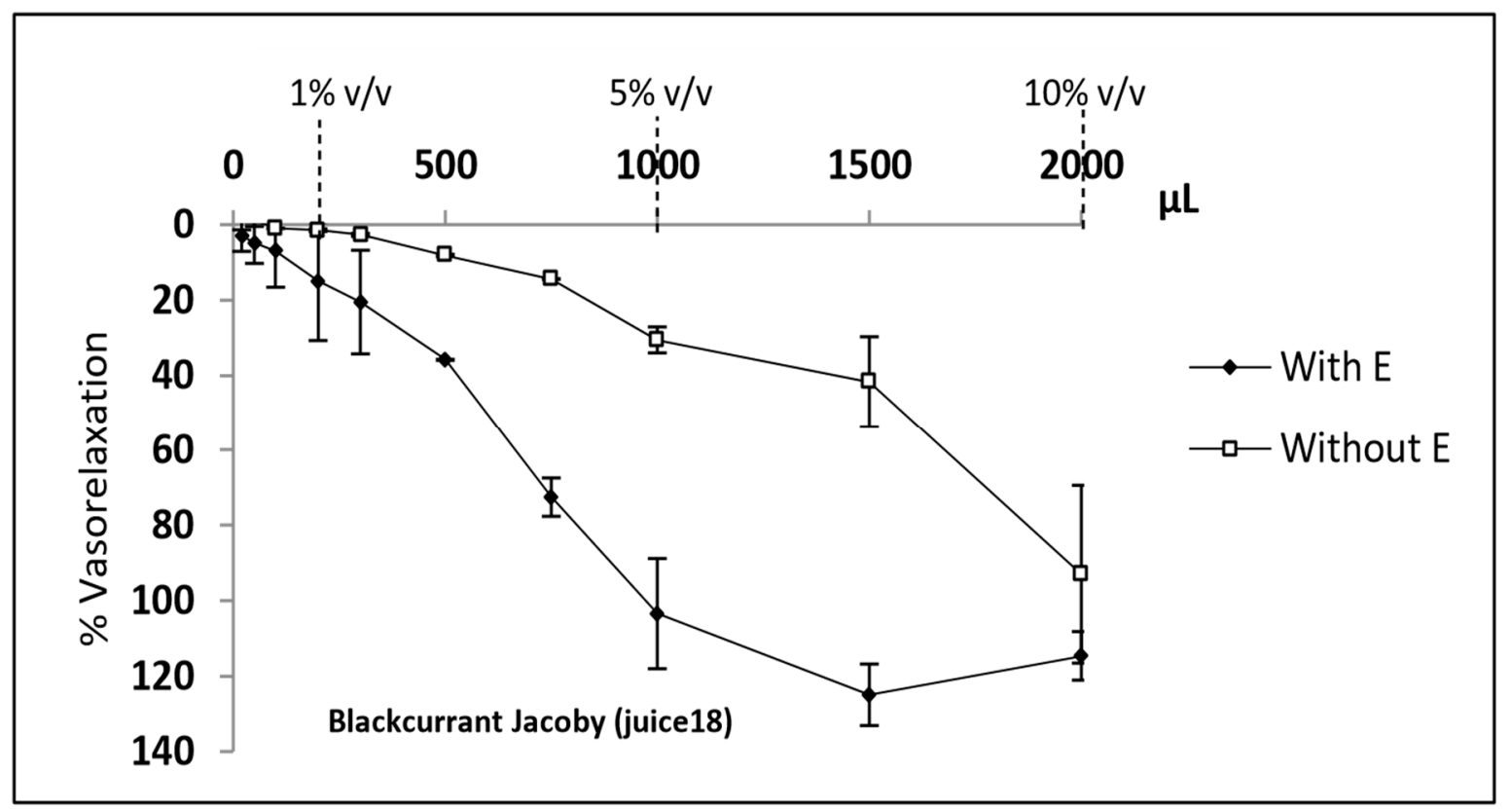

(A)

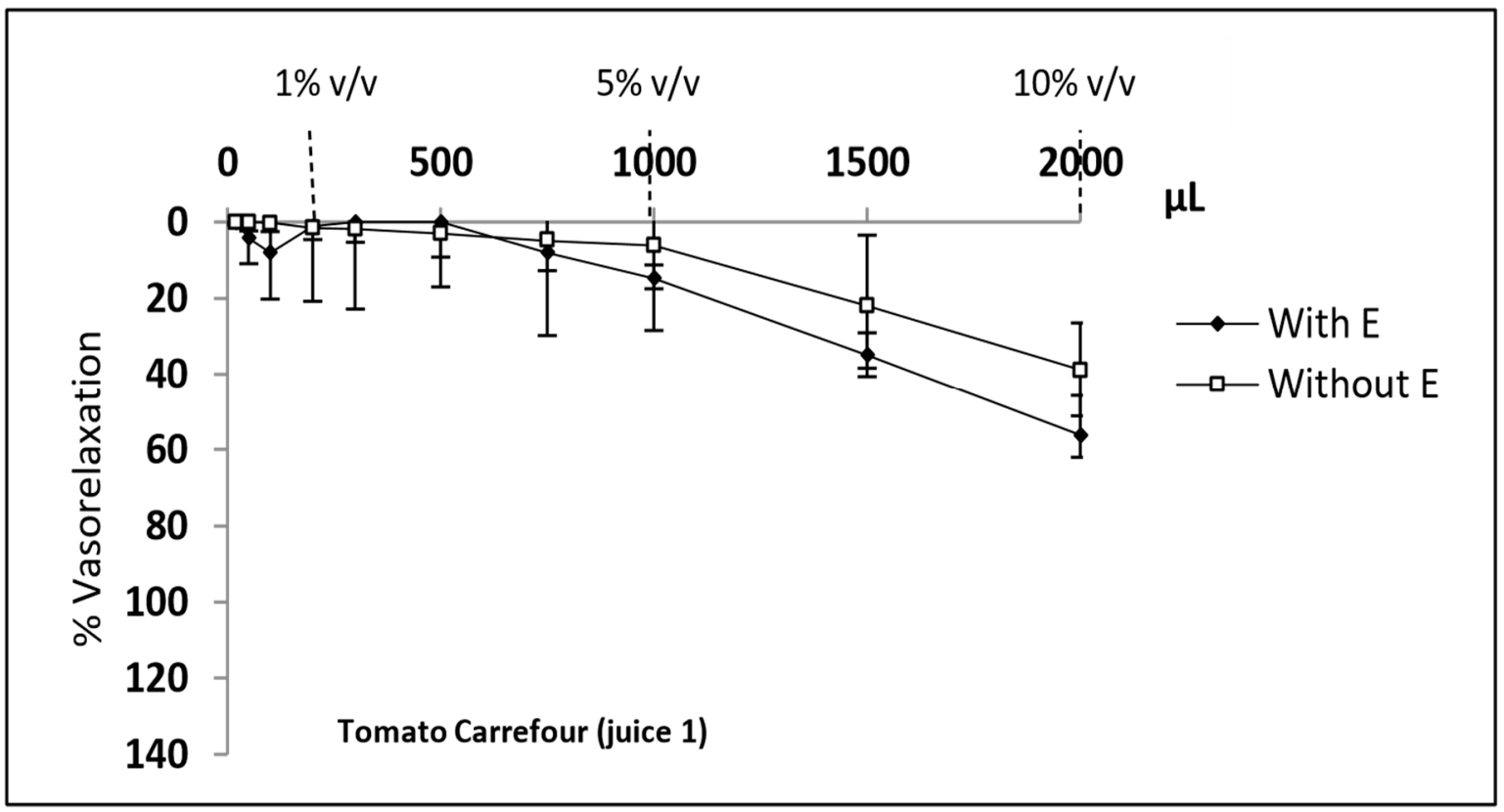

(B)

Figure 1. Examples of endothelial vasorelaxation activity in segments of rat aorta according to the volume of either blackcurrant (Jacoby) and Tomato (Carrefour) juices (respectively panels $\mathbf{A}$ and $\mathbf{B}$ ) added to $20 \mathrm{~mL}$ initial organ bath solution (OBS). The following $\mathrm{V}_{\text {juice }} / \mathrm{V}_{\text {OBS }}$ ratios were selected to evaluate the vasorelaxant effect as a function of total or individual concentrations of specific phenolic compounds: $1 \%, 5 \%$, and $10 \%$. Cumulative volumes of each fruit or vegetable juice were then added to reach a final volume of $2000 \mu \mathrm{L}$ over a period of $1 \mathrm{~h} . \mathrm{E}=$ endothelium.

\subsection{Statistical Analyses}

Correlations between $\mathrm{E}^{+}$and TPC-J (expressed in $\mu \mathrm{g} \mathrm{GAE} / \mathrm{mL}$ ), total polyphenols in the juice-containing $\mathrm{OB}$ (TPC-OB, expressed in $\mu \mathrm{g} \mathrm{GAE} / \mathrm{mL}$ ), and total and individual flavonols, 
flavanols, and anthocyanins in the juice-containing OB (expressed in $\mu \mathrm{g} / \mathrm{mL}$ ) were calculated with Sisvar 5.6 software. Pearson correlations were considered significant at $p<0.05$.

\section{Results}

As shown in Figure 2, the range of TPC-J values was wide. Juice 1 (Tomato, Carrefour) showed the lowest value $(214 \mu \mathrm{g} \mathrm{GAE} / \mathrm{mL})$ and juice 9 (Grape, Materne), the highest (1564 $\mu \mathrm{g} \mathrm{GAE} / \mathrm{mL})$. The mean TPC-J for the juices investigated was $843 \pm 396 \mu \mathrm{g} \mathrm{GAE} / \mathrm{mL}$. The juices also differed greatly in total flavonol and total flavanol contents, as shown in Table 1. Juice 3 (Carrot, Biotta) had the lowest flavonol content $(0.8 \mu \mathrm{g} / \mathrm{mL})$ and juice 12 (Blackcurrant Biotta), the highest $(17.7 \mu \mathrm{g} / \mathrm{mL})$. For flavanols, the lowest $(2.62 \mu \mathrm{g} / \mathrm{mL})$ and highest values $(236 \mu \mathrm{g} / \mathrm{mL})$ were observed, respectively, for juice 6 (Lemon, Bonneterre) and juice 18 (Blackcurrant, Jacoby). The average flavonol and flavanol concentrations were respectively $6.3 \pm 4.7$ and $109 \pm 249 \mu \mathrm{g} / \mathrm{mL}$. If one excludes juice 11, which reached $1194 \mu \mathrm{g} / \mathrm{mL}$, the average flavanol concentration was $57.7 \pm 58.2 \mu \mathrm{g} / \mathrm{mL}$.

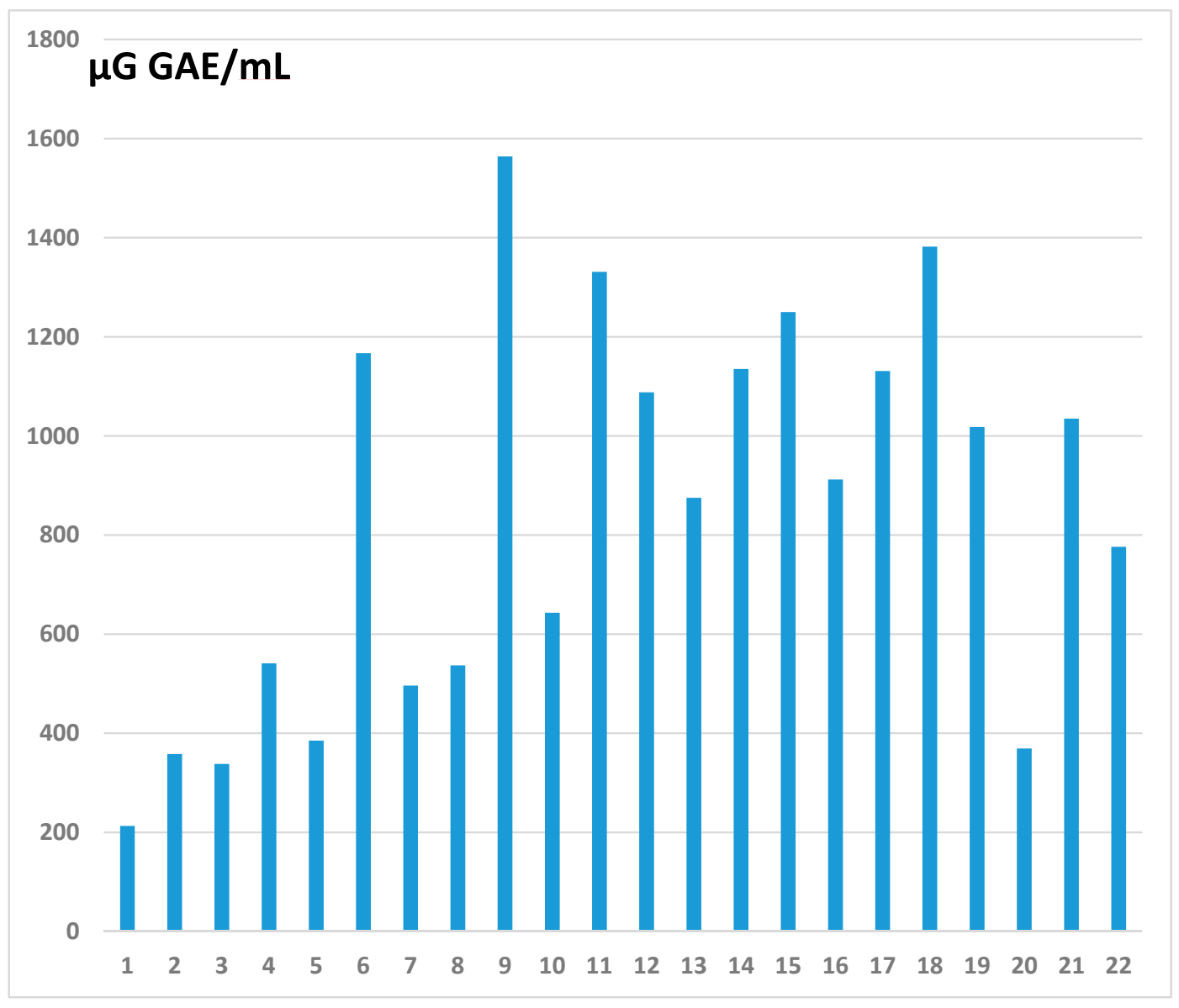

Figure 2. Total polyphenol contents (TPC-J), expressed in $\mu \mathrm{g}$ gallic acid equivalents per milliliter ( $\mu \mathrm{g}$ GAE/mL), of 22 commercial vegetable and fruit juices found in Belgian and French markets. GAE: gallic acid equivalents. 1: Tomato (Carrefour), 2: Tomato (Biotta), 3: Carrot (Biotta), 4: Orange d'Espagne (Carrefour), 5: Pure Orange (Vitamont), 6: Lemon (Bonneterre), 7: Grapefruit, 8: Pure Grapefruit (Vitamont), 9: Grape (Materne), 10: Pure Grape (Vitamont), 11: Pomegranate (Biotta), 12: Blackcurrant (Biotta), 13: Blackcurrant (Natreen), 14: Blackcurrant (Jacoby Bio), 15: Blackcurrant (Van Nahmen), 16: Blackcurrant (Schörl Nectar), 17: Blackcurrant (Gut and Günstig), 18: Blackcurrant (Jacoby), 19: Pineapple Juice (Carrefour), 20: Pineapple Juice (De Drie Wilgen), 21: Apple (Carrefour), and 22: Pure Apple (Vitamont). 
Table 1. Individual and total flavonol and flavanol contents $(\mu \mathrm{g} / \mathrm{mL})$ of 22 commercial vegetable and fruit juices.

\begin{tabular}{|c|c|c|c|c|c|c|c|c|c|c|c|c|}
\hline number & List of Juices & Myricetin & Quercetin & Kaempferol & Total Flavonols & EGC & EGCG & ECG & GC & $\mathrm{C}$ & EC & Total Flavanols \\
\hline 1 & Tomato (Carrefour) & 0.3 & 2.7 & 0.1 & 3.1 & 2.74 & 8.86 & 1.64 & 53.55 & 0.05 & 4.34 & 71.19 \\
\hline 2 & Tomato (Biotta) & 0.1 & 1.6 & 0.2 & 1.9 & 14.40 & 8.34 & 3.89 & 26.70 & 0.06 & 2.67 & 56.06 \\
\hline 3 & Carrot (Biotta) & 0.1 & 0.5 & 0.2 & 0.8 & 0.71 & 29.64 & 1.58 & 0.00 & 0.32 & 0.85 & 33.09 \\
\hline 4 & Orange d'Espagne (Carrefour) & 0.5 & 0.9 & 0.1 & 1.5 & 20.47 & 7.91 & 1.57 & 0.60 & 0.21 & 0.22 & 30.97 \\
\hline 5 & Pure Orange (Vitamont) & 1.3 & 0.8 & 0.7 & 2.8 & 7.69 & 2.67 & 2.19 & 1.53 & 0.09 & 1.09 & 15.25 \\
\hline 6 & Lemon (Bonneterre) & 0.7 & 1.3 & 1.9 & 4.0 & 0.52 & 0.86 & 0.42 & 0.11 & 0.03 & 0.68 & 2.62 \\
\hline 7 & Grapefruit & 1.8 & 2.0 & 1.1 & 4.9 & 4.18 & 1.48 & 0.85 & 0.24 & 0.14 & 3.15 & 10.03 \\
\hline 8 & Pure Grapefruit (Vitamont) & 0.6 & 0.9 & 0.5 & 2.0 & 9.67 & 1.99 & 1.38 & 0.03 & 0.04 & 4.66 & 17.76 \\
\hline 9 & Grape Materne (Materne) & 13.0 & 2.7 & 0.4 & 16.0 & 86.68 & 41.37 & 14.43 & 3.89 & 1.11 & 7.51 & 154.99 \\
\hline 10 & Pure Grape (Vitamont) & 7.6 & 3.3 & 0.9 & 11.9 & 5.63 & 11.79 & 8.85 & 0.27 & 0.36 & 1.81 & 28.71 \\
\hline 11 & Pomegranate (Biotta) & 8.5 & 4.0 & 0.2 & 12.7 & 849.59 & 45.95 & 3.00 & 294.60 & 0.09 & 0.77 & 1194 \\
\hline 12 & Blackcurrant (Biotta) & 14.4 & 2.5 & 0.7 & 17.7 & 13.85 & 37.80 & 7.11 & 2.00 & 0.02 & 0.63 & 61.41 \\
\hline 13 & Blackcurrant (Natreen) & 4.8 & 3.5 & 0.0 & 8.3 & 23.00 & 18.42 & 2.10 & 1.20 & 0.10 & 1.39 & 46.22 \\
\hline 14 & Blackcurrant (Jacoby Bio) & 1.6 & 2.2 & 0.3 & 4.1 & 21.81 & 33.17 & 1.73 & 4.29 & 0.26 & 2.17 & 63.43 \\
\hline 15 & Blackcurrant (Van Nahmen) & 1.8 & 2.7 & 0.5 & 4.9 & 22.60 & 66.02 & 2.78 & 10.76 & 0.33 & 1.71 & 104.20 \\
\hline 16 & Blackcurrant (Schlör nectar) & 2.0 & 1.9 & 0.3 & 4.2 & 22.68 & 41.27 & 1.96 & 6.41 & 0.22 & 0.84 & 73.39 \\
\hline 17 & Blackcurrant (Gut and Günstig) & 1.9 & 2.7 & 0.6 & 5.1 & 21.90 & 95.06 & 4.46 & 7.77 & 0.35 & 2.31 & 131.85 \\
\hline 18 & Blackcurrant (Jacoby) & 3.2 & 3.3 & 0.7 & 7.2 & 44.05 & 181.42 & 3.25 & 4.65 & 0.60 & 2.07 & 236.02 \\
\hline 19 & Pineapple juice (Carrefour) & 7.7 & 1.6 & 1.2 & 10.5 & 1.74 & 4.66 & 1.12 & 0.32 & 0.12 & 3.59 & 11.55 \\
\hline 20 & Pineapple juice (De Drie Wilgen) & 1.6 & 0.9 & 0.4 & 2.9 & 8.32 & 14.06 & 4.94 & 18.94 & 0.02 & 2.40 & 48.67 \\
\hline 21 & Apple (Carrefour) & 1.3 & 2.3 & 1.0 & 4.5 & 1.26 & 3.17 & 1.37 & 0.03 & 0.11 & 0.45 & 6.39 \\
\hline 22 & Pure Apple (Vitamont) & 3.5 & 4.0 & 0.3 & 7.9 & 1.32 & 2.87 & 2.80 & 0.04 & 0.14 & 0.74 & 7.91 \\
\hline
\end{tabular}


Among the 22 tested juices, only the 10 red ones (blackcurrant, grape, pomegranate) contained detectable levels of anthocyanins (Figure 3). Among these, the total anthocyanin content varied widely, from $16 \mu \mathrm{g} / \mathrm{mL}$ (Pure Grape, Vitamont) to $338 \mu \mathrm{g} / \mathrm{mL}$ (Blackcurrant, Jacoby Bio). We calculated mean total anthocyanin contents of $125 \pm 99 \mu \mathrm{g} / \mathrm{mL}$ for the 10 red juices and $159 \pm 99 \mu \mathrm{g} / \mathrm{mL}$ for the seven blackcurrant juices considered alone.

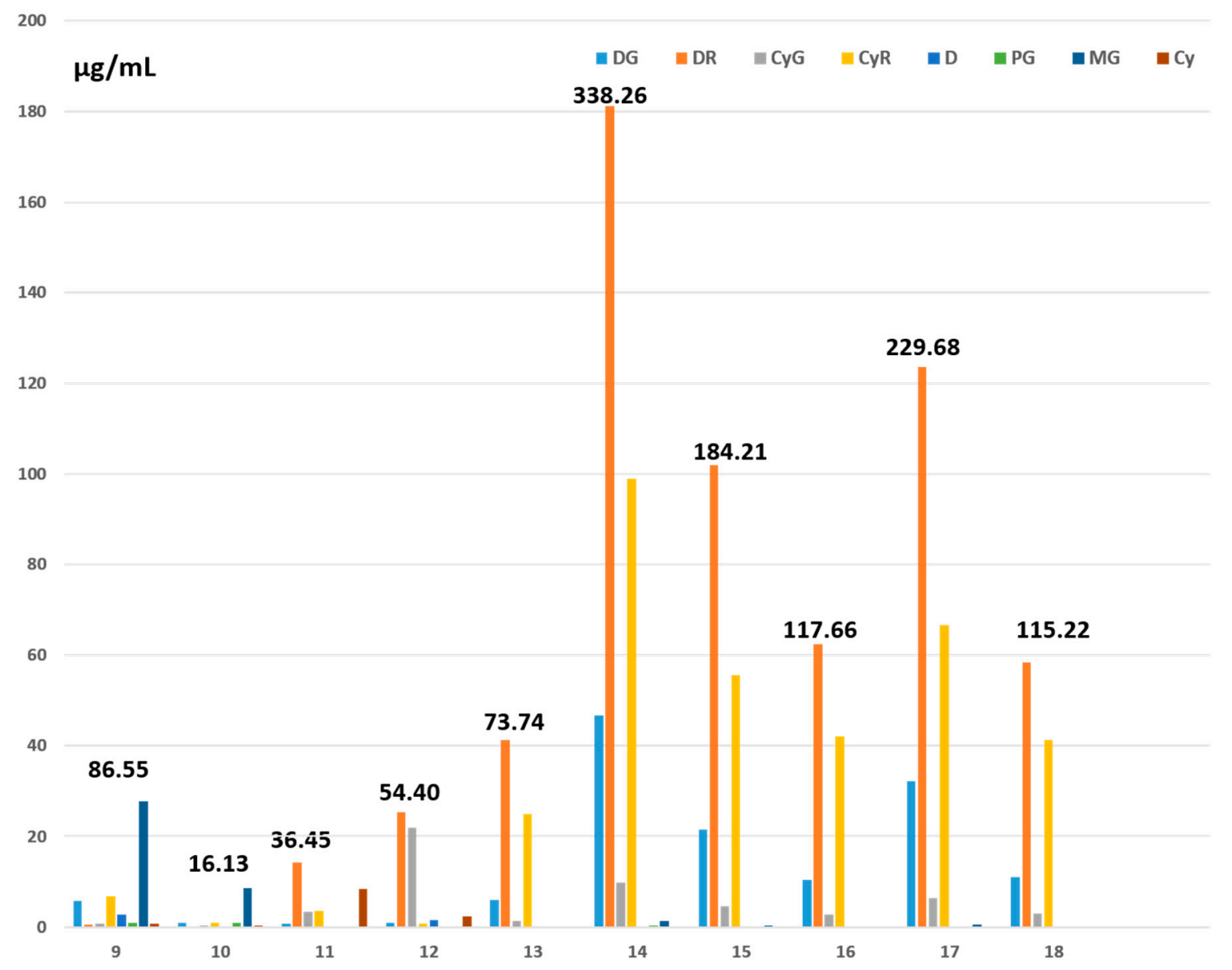

Figure 3. Concentrations of individual anthocyanins $(\mu \mathrm{g} / \mathrm{mL})$ found in 10 commercial red fruit juices. Numbers in bold indicate total anthocyanin concentrations $(\mu \mathrm{g} / \mathrm{mL})$ in the juices. Pet, Pel, P, and M are not represented because of their low to zero concentrations in the juices. 9. Grape Materne (Carrefour), 10. Pure Grape (Vitamont), 11. Pomegranate (Biotta), 12. Blackcurrant (Biotta), 13. Blackcurrant (Natreen), 14. Blackcurrant (Jacoby Bio), 15. Blackcurrant (Van Nahmen), 16. Blackcurrant (Schörl Nectar), 17. Blackcurrant (Gut and Günstig), and 18. Blackcurrant (Jacoby).

Table 2 shows the percentages of vasorelaxation $\mathrm{E}^{+}$and $\mathrm{E}^{-}$elicited by the 22 individual fruit and vegetable juices at three $\mathrm{V}_{\text {juice }} / \mathrm{V}_{\mathrm{OBS}}$ ratios (henceforth called "volume ratios"): $1 \%, 5 \%$, and $10 \%$. Juices issued from vegetables (tomato and carrot) gave rise to a very low $\mathrm{E}^{+}$when added at volume ratio $1 \%$ or $5 \%$. At volume ratio $10 \%$, however, the $\mathrm{E}^{+}$reached $56 \%$ for juice Tomato, Carrefour, which caused similar vasorelaxation (38.83\%) even after removal of the endothelium. All but one of the citrus juices exerted no vasorelaxant effect at volume ratio $1 \%$, whether the endothelium was present or not. The exception was lemon juice, which elicited a very high percentage of vasorelaxation $(81.07 \%)$ at this volume ratio, in the presence and absence of endothelium. At volume ratio 10\%, the vasorelaxation caused by the other citrus juices increased up to $61.7-120 \%$, both in the presence and absence of endothelium. Among the berry juices, those issued from blackcurrant clearly exerted the greatest vasorelaxant effect. At volume ratio 1\%, all of these except juices 13 and 14 gave rise to a substantial $\mathrm{E}^{+}$, the highest values being observed with juices $12(44.75 \%)$ and 18 (56.76\%). No significant vasorelaxant 
effect was observed in the absence of endothelium. At volume ratio $5 \%$, all the blackcurrant juices elicited an $\mathrm{E}^{+}$close or equal to $100 \%$, but vasorelaxant effects were also evidenced without endothelium, albeit to a lesser extent: 41 to $67 \%$. At volume ratio $10 \%$, each blackcurrant juice gave rise to both $\mathrm{E}^{+}$ and $\mathrm{E}^{-}$values equal or superior to $100 \%$. 
Table 2. Ability of 22 commercial vegetable and fruit juices to induce vasorelaxation in segments of rat aorta. $\mathrm{E}^{+}$and $\mathrm{E}^{-}$represent percentages of vasorelaxation observed at three $\mathrm{V}_{\text {juice }} / \mathrm{V}_{\text {OBS }}$ ratios $(1 \%, 5 \%$, and $10 \%)$, respectively in the presence $(+)$ and absence (-) of endothelium.

\begin{tabular}{|c|c|c|c|c|c|c|c|}
\hline \multirow{2}{*}{ Number } & \multirow{2}{*}{ Juices Origin } & \multicolumn{3}{|c|}{ With Endothelium } & \multicolumn{3}{|c|}{ Without Endothelium } \\
\hline & & $\mathrm{E}^{+}(1 \% v / v)$ & $\mathrm{E}^{+}(5 \% v / v)$ & $\mathrm{E}^{+}(10 \% v / v)$ & $\mathrm{E}^{-}(1 \% v / v)$ & $\mathrm{E}^{-}(5 \% v / v)$ & $\mathrm{E}^{-}(10 \% v / v)$ \\
\hline 1 & Tomato (Carrefour) & $1.19 \pm 22.87$ & $14.73 \pm 3.44$ & $56.19 \pm 10.44$ & $1.51 \pm 3.1$ & $6.07 \pm 11.49$ & $38.83 \pm 12.3$ \\
\hline 2 & Tomato (Biotta) & & $6.9 \pm 7.73$ & $28.82 \pm 9.63$ & & $30.58 \pm 5.85$ & $79.82 \pm 7.50$ \\
\hline 3 & Carrot (Biotta) & $4.28 \pm 6.7$ & $7.72 \pm 6.39$ & $44.94 \pm 18.26$ & $8.52 \pm 1.84$ & $35.24 \pm 9.45$ & $63.41 \pm 22.19$ \\
\hline 4 & Orange d'Espagne (Carrefour) & & $27.86 \pm 27.04$ & $61.70 \pm 30.32$ & $6.1 \pm 14.35$ & $25.79 \pm 16.05$ & $49.68 \pm 24.24$ \\
\hline 5 & Pure Orange (Vitamont) & & $40.63 \pm 30.89$ & $83.27 \pm 21.00$ & $4.11 \pm 4.75$ & $122.9 \pm 66.61$ & $173.14 \pm 89.22$ \\
\hline 6 & Lemon (Bonneterre) & $81.07 \pm 9.9$ & $95.06 \pm 13.4$ & $87.32 \pm 10.97$ & $79.35 \pm 1.49$ & $102.04 \pm 1.25$ & $98.48 \pm 1.11$ \\
\hline 7 & Grapefruit & & $16.64 \pm 17.04$ & $74.39 \pm 1.34$ & & $36.17 \pm 10.46$ & $89.68 \pm 2.70$ \\
\hline 8 & Pure Grapefruit (Vitamont) & $15.01 \pm 0.00$ & $106.56 \pm 6.86$ & $120.43 \pm 7.10$ & & $102.49 \pm 6.86$ & $105.41 \pm 7.10$ \\
\hline 9 & Grape Materne (Materne) & $8.81 \pm 0.80$ & $22.98 \pm 5.50$ & $45.11 \pm 9.58$ & & $16.77 \pm 4.51$ & $40.49 \pm 4.12$ \\
\hline 10 & Pure Grape (Vitamont) & $15.01 \pm 0.23$ & $20.06 \pm 12.54$ & $56.19 \pm 11.05$ & $0.18 \pm 17.56$ & $25.76 \pm 22.59$ & $38.83 \pm 1.92$ \\
\hline 11 & Pomegranate (Biotta) & & $93.13 \pm 8.42$ & $106.78 \pm 5.67$ & $2.09 \pm 1.91$ & $59.35 \pm 17.94$ & $92.34 \pm 19.73$ \\
\hline 12 & Blackcurrant (Biotta) & $44.75 \pm 22.76$ & $97.29 \pm 26.8$ & $110.15 \pm 15.87$ & $4.56 \pm 7.66$ & $40.56 \pm 22.31$ & $94.35 \pm 27.06$ \\
\hline 13 & Blackcurrant (Natreen) & $9.47 \pm 16.59$ & $106.55 \pm 4.19$ & $114.65 \pm 13.14$ & & $42.59 \pm 31.06$ & $66.56 \pm 30.63$ \\
\hline 14 & Blackcurrant (Jacoby Bio) & $5.12 \pm 0.92$ & $96.59 \pm 12.4$ & $191.68 \pm 3.81$ & & $44.21 \pm 12.37$ & $91.57 \pm 18.88$ \\
\hline 15 & Blackcurrant (Van Nahmen) & $19.9 \pm 0.97$ & $100.53 \pm 5.08$ & $109.73 \pm 7.52$ & $2.76 \pm 42.66$ & $64.48 \pm 25.82$ & $127.59 \pm 18.8$ \\
\hline 16 & Blackcurrant (Schörl nectar) & $23.75 \pm 3.59$ & $85.57 \pm 20.41$ & $117.41 \pm 8.91$ & $1.64 \pm 0.14$ & $42.07 \pm 20.44$ & $87.59 \pm 26.57$ \\
\hline 17 & Blackcurrant (Gut \& Günstig) & $19.99 \pm 14.51$ & $85.88 \pm 8.10$ & $107.18 \pm 2.61$ & & $52.29 \pm 9.00$ & $110.93 \pm 7.56$ \\
\hline 18 & Blackcurrant (Jacoby) & $56.76 \pm 24.49$ & $103.82 \pm 5.07$ & $106.1 \pm 7.97$ & $0.87 \pm 1.23$ & $67.53 \pm 15.57$ & $103.43 \pm 4.16$ \\
\hline 19 & Pineapple juice (Carrefour) & $5.66 \pm 14.96$ & $13.04 \pm 6.9$ & $35.46 \pm 2.12$ & & $9.1 \pm 7.54$ & $38.19 \pm 20.4$ \\
\hline 20 & Pineapple juice (De Drie Wilgen) & & $12.95 \pm 2.19$ & $92.05 \pm 0.72$ & & $5.88 \pm 1.58$ & $34.15 \pm 5.00$ \\
\hline 21 & Apple (Carrefour) & & & $29.23 \pm 6.97$ & & $0.98 \pm 3.23$ & $17.83 \pm 1.34$ \\
\hline 22 & Pure Apple (Viamont & $15.28 \pm 4.75$ & $64.01 \pm 4.29$ & $86.64 \pm 11.96$ & & $32.38 \pm 19.4$ & $68.68 \pm 27.3$ \\
\hline
\end{tabular}


From the data in Figures 2 and 3 and Table 1, it was possible to calculate for each OB the concentrations (in $\mu \mathrm{g} / \mathrm{mL}$ ) of total polyphenols (TPC-OB) and total and individual flavonols, flavanols, and anthocyanins and to establish correlations suggesting which compounds might be responsible for observed vasorelaxant effects. As depicted in Table 3, TPC-OB correlated significantly with $\mathrm{E}^{+}$at volume ratios $5 \%(r=0.58, p=0.04)$ and $10 \%(r=0.55, p=0.007)$. No correlation was found between $\mathrm{E}^{+}$and total flavonols or flavanols present in the OB. A strong, significant correlation was found between $\mathrm{E}^{+}$and total anthocyanins issued from berry juices added at volume ratio $10 \%$ $(r=0.75, p=0.05)$. For the flavonol family, the only correlation evidenced was between kaempferol and the $\mathrm{E}^{+}$at ratio $1 \%(r=0.56, p=0.009)$. For the flavanol compounds, the only correlation observed was between EGCG and the $\mathrm{E}^{+}$at volume ratios $1 \%(r=0.41, p=0.05)$ and $5 \%(r=0.45, p=0.03)$. For the anthocyanin family, no correlation was evidenced at ratio $1 \%$ between the $\mathrm{E}^{+}$and the concentration of any individual compound in the OB. At ratio 5\%, MG and especially PG from red juices (especially blackcurrant) correlated significantly with the $\mathrm{E}^{+}$(respectively $r=0.8, p<0.05$ and $r=0.96, p<0.00001$ ). At ratio $10 \%$, the concentrations of DG, DR, and CyR correlated significantly with the $\mathrm{E}^{+}$.

Table 3. Correlations between $\mathrm{E}^{+}$and TPC-J, TPC-OB, and total and individual OB concentrations of juice flavonols, flavanols, and anthocyanins, according to the volume of juice added to $20 \mathrm{~mL}$ initial OB solution $\left(\mathrm{V}_{\text {juice }} / \mathrm{V}_{\mathrm{OBS}}\right.$ ratios $1 \%, 5 \%$, and $\left.10 \%\right)$. $\mathrm{E}^{+}$represent percentages of vasorelaxation observed at three $\mathrm{V}_{\text {juice }} / \mathrm{V}_{\mathrm{OBS}}$ ratios in the presence of endothelium.

\begin{tabular}{|c|c|c|c|c|c|c|}
\hline \multirow{2}{*}{ Compounds } & \multicolumn{2}{|c|}{$\mathrm{E}^{+}(1 \% v / v)$} & \multicolumn{2}{|c|}{$\mathrm{E}^{+}(5 \% v / v)$} & \multicolumn{2}{|c|}{$\mathrm{E}^{+}(10 \% v / v)$} \\
\hline & $r$ & $p$-Value & $r$ & $p$-Value & $r$ & $p$-Value \\
\hline TPC-J & 0.32 & 0.14 & 0.58 & 0.04 & 0.55 & 0.007 \\
\hline TPC-OB & 0.32 & 0.14 & 0.58 & 0.04 & 0.55 & 0.007 \\
\hline Flavonols-OB & 0.19 & 0.39 & 0.17 & 0.44 & 0.02 & 0.99 \\
\hline Flavanols-OB & 0.08 & 0.69 & 0.27 & 0.2 & 0.17 & 0.44 \\
\hline Anthocyanins-OB & 0.54 & 0.2 & 0.28 & 0.5 & 0.75 & 0.05 \\
\hline Myricetin & 0.1 & 0.6 & 0.06 & 0.7 & 0.07 & 0.7 \\
\hline Quercetin & 0.11 & 0.61 & 0.35 & 0.1 & 0.19 & 0.38 \\
\hline Kaempferol & 0.56 & 0.009 & 0.11 & 0.96 & 0.19 & 0.4 \\
\hline EGC & 0.14 & 0.51 & 0.22 & 0.31 & 0.13 & 0.54 \\
\hline EGCG & 0.41 & 0.05 & 0.45 & 0.03 & 0.31 & 0.15 \\
\hline ECG & 0.004 & 0.98 & 0.13 & 0.5 & 0.17 & 0.44 \\
\hline GC & 0.19 & 0.3 & 0.14 & 0.5 & 0.09 & 0.68 \\
\hline $\mathrm{C}$ & 0.07 & 0.75 & 0.03 & 0.87 & 0.09 & 0.67 \\
\hline $\mathrm{EC}$ & 0.19 & 0.37 & 0.2 & 0.35 & 0.16 & 0.45 \\
\hline DG & 0.17 & 0.6 & 0.3 & 0.39 & 0.70 & 0.02 \\
\hline DR & 0.06 & 0.85 & 0.49 & 0.14 & 0.81 & 0.004 \\
\hline CyG & 0.38 & 0.26 & 0.37 & 0.28 & 0.39 & 0.25 \\
\hline CyR & 0.06 & 0.86 & 0.44 & 0.2 & 0.76 & 0.01 \\
\hline PG & 0.49 & 0.28 & 0.96 & 0.00001 & 0.61 & 0.1 \\
\hline MG & 0.36 & 0.2 & 0.8 & 0.05 & 0.61 & 0.11 \\
\hline
\end{tabular}

As shown on Table 4, the mass concentrations of phenolic compounds in each OB were converted to molar concentrations. For each volume ratio, these concentrations were averaged over all the juice-containing organ baths. The results show that an E+ was observed at all three ratios at average quercetin, kaempferol, ECG, C, EC, CyG, and PG concentrations below $1 \mu \mathrm{M}$. This was also the case for myricetin but only at ratios $1 \%$ and $5 \%$. The average concentrations of EGC, EGCG, GC, DG, DR, CyR, and MG were above $1 \mu \mathrm{M}$. 
Table 4. Conversion of individual flavonol, flavanol, and anthocyanin mass concentrations to molarities $(\mu \mathrm{M})$. The indicated values are the means \pm SD calculated for the whole set of juices. ${ }^{*}$ For EGC and GC, values related to juice 11 (pomegranate) were removed for the three ratios because being aberrant.

\begin{tabular}{cccc}
\hline \multirow{2}{*}{ Compounds } & \multicolumn{3}{c}{ Title } \\
\cline { 2 - 4 } & $\mathbf{V}_{\text {juice }} / \mathbf{V}_{\text {OBS }} \mathbf{1 \%}$ & $\mathbf{V}_{\text {juice }} / \mathbf{V}_{\text {OBS }} \mathbf{5} \%$ & $\mathbf{V}_{\text {juice }} / \mathbf{V}_{\text {OBS }} \mathbf{1 0} \%$ \\
\hline \multirow{3}{c}{ flavonols $(\mu \mathrm{M})$} \\
myricetin & $0.12 \pm 0.13(0.005-0.11)$ & $0.56 \pm 0.62(0.022-2.60)$ & $1.06 \pm 1.18(0.042-4.12)$ \\
quercetin & $0.07 \pm 0.03(0.17-0.62)$ & $0.34 \pm 0.16(0.080-0.623)$ & $0.66 \pm 0.31(0.15-1.2)$ \\
kaempferol & $0.02 \pm 0.02(0.006-0.67)$ & $0.09 \pm 0.07(0.024-0.32)$ & $0.18 \pm 0.14(0.046-0.615)$ \\
& \multicolumn{2}{c}{ flavanols $(\mu \mathrm{M})$} \\
EGC & $0.51 \pm 0.60(0.02-2.8)^{*}$ & $2.5 \pm 3.0(0.08-6.8)^{*}$ & $4.8 \pm 5.9(0.21-6.8)^{*}$ \\
EGCG & $0.6 \pm 0.9(0.02-3.9)$ & $3.10 \pm 4.4(0.09-19)$ & $6.0 \pm 8.3(0.17-36)$ \\
ECG & $0.1 \pm 0.1(0.01-0.32)$ & $0.4 \pm 0.4(0.05-1.60)$ & $0.7 \pm 0.7(0.09-3)$ \\
GC & $0.23 \pm 0.4(0.01-1.7)^{*}$ & $1.1 \pm(0.01-8.3)^{*}$ & $2.03 \pm 3.8(0.01-16)^{*}$ \\
C & $0.01 \pm 0.01(0.002-0.38)$ & $0.04 \pm 0.04(0.004-0.18)$ & $0.1 \pm 0.1(0.007-0.35)$ \\
EC & $0.1 \pm 0.1(0.02-0.26)$ & $0.3 \pm 0.3(0.04-1.20)$ & $0.7 \pm 0.6(0.07-2.40)$ \\
anthocyanins $(\mu \mathrm{M})$ & \\
DG & $0.29 \pm 0.3(0.02-0.99)$ & $1.39 \pm 1.6(0.08-4.76)$ & $2.66 \pm 3.0(0.14-9.10)$ \\
DR & $1.97 \pm 1.9(0.01-5.90)$ & $9.48 \pm 9.1(0.03-28)$ & $18.22 \pm 17.6(0.06-54)$ \\
CyG & $0.12 \pm 0.10(0.01-0.48)$ & $0.57 \pm 0.7(0.05-2.30)$ & $1.10 \pm 1.3(0.09-4.42)$ \\
CyR & $0.45 \pm 0.40(0.01-1.30)$ & $2.15 \pm 2.10(0.05-6.20)$ & $4.11 \pm 4.0(0.10-12)$ \\
PG & $0.01 \pm 0.01(0.01-0.02)$ & $0.04 \pm 0.04(0.02-0.11)$ & $0.08 \pm 0.07(0.04-0.21)$ \\
MG & $>10 \quad>20$ & $>20$ \\
\hline
\end{tabular}

\section{Discussion}

Many studies have evidenced that the intake of fruits and vegetables exerts potent protection against cardiovascular diseases and cancers [19-22]. All these effects have been attributed to the presence, in these foods, of antioxidants, namely polyphenols. Great attention has been paid to the cardioprotective effect of polyphenols, linked to their ability to prevent endothelial dysfunction thanks to restoration of vasodilator nitric oxide (NO) production through expression of endothelial nitric oxide synthase (eNOS) or through activation of endothelium hyperpolarization [23]. However, whether a similar link exists between cardioprotection and vegetable or fruit juice consumption is not so clear, notably because juices contain less fiber than fruits and vegetables. In 2005, Ruxton et al. [24] published a review of epidemiological and small clinical studies showing only a minor impact of fruit and vegetable juices on cancers, as compared to their greater impact on cardiovascular diseases. More recently, Hyson [25] confirmed these cancer data in a critical analysis of the scientific literature related to fruit juices and human health. The same author, however, highlighted that interventional studies with acute or chronic intake of different juices (apple, orange, mandarin, grape, cranberry, pomegranate) resulted in decreased levels of some oxidative stress biomarkers associated with increased cardiovascular risk (lipid peroxides, oxidized LDL, carbonyl groups). Khan et al. [26] have described similar observations with polyphenol-rich blackcurrant juice. To better understand the potential cardioprotective effect of fruit and vegetable juices, it is thus necessary to examine in detail how they differ in polyphenol content and composition. Surprisingly, little information is available on this topic.

Among our 22 tested juices, those prepared from lemon (juice 6), pineapple (juice 19), apple (juice 21), and especially red fruits (juices 9 to 18) clearly exhibited the highest TPC-J values. Using home-made preparations, Tzulker et al. [27] found antioxidant activity, as evidenced in DPPH assays, to correlate significantly with the TPC-J in 29 different pomegranate accessions. They gave further details about levels of total anthocyanins and four major hydrolyzable tannins. Using HPLC-PDA-MS (high performance liquid chromatography-photo diode array-mass spectrometry), Borges et al. [28] later analyzed the TPC-J values of 26 commercial pomegranate juices produced in Europe, identifying ellagitannins as the major antioxidants in these juices. Nowak et al. [29] compared the TPC-J values of 
five organic juices extracted from elderberry, pomegranate, cranberry, and chokeberry $(n=2)$. They observed the highest TPC-J in chokeberry juice, the predominant polyphenols being anthocyanins and phenolic acids. Granato et al. [30] examined the TPC-J of 20 organic fruit juices (cranberry, pomegranate, blueberry, elderberry, apple, and orange) acquired in local shops in the Netherlands. The pomegranate and elderberry juices exhibited the highest TPC-J (respective mean values: 2684 and $3521 \mu \mathrm{g} \mathrm{GAE} / \mathrm{mL}$ ). Apple and orange juices were found, respectively, to contain 399 and $470 \mu \mathrm{g}$ GAE/mL. Wern et al. [31] report a TPC-J of $133 \mu \mathrm{g}$ GAE/mL for fresh pomegranate juice purchased from local markets or hypermarkets in Kuala Lumpur, Malaysia, as compared to values between 3000 and $4070 \mathrm{mg}$ GAE/100 mL for juices from cultivars in Spain [32] and 3150-7430 mg GAE/100 mL for juices from Chinese cultivars [33]. Here we find our selected pomegranate juice of Spanish origin to contain $1331 \mu \mathrm{g} \mathrm{GAE} / \mathrm{mL}$. As compared to the results obtained by Granato et al. [30], the TPC-J values of our orange juices (Table 1) are similar but those of our two tested apple juices are higher TPC-J (1035 and $776 \mu \mathrm{g} \mathrm{GAE} / \mathrm{mL}$ ). Auger et al. [34] found a TPC-J ranging from 0.31 to $1860 \mu \mathrm{g} \mathrm{GAE} / \mathrm{mL}$ in 51 commercial fruit juices (grape $(n=12)$, blackcurrant $(n=7)$, cranberry $(n=5)$, apple $(n=6)$, orange $(n=5)$, red fruit $(n=6)$, blend of red fruits $(n=6)$, and non-red fruits $(n=4))$. Among all these juices, the highest TPC-J was observed in those extracted from blackcurrant. Among the ten red juices investigated in our study, seven are blackcurrant juices. As shown in Table 1, we have found the TPC-J to vary among blackcurrant juices (from 875 to $1382 \mu \mathrm{g} \mathrm{GAE} / \mathrm{mL}$ ). We have calculated a mean value of $1110 \pm 177 \mu \mathrm{g} \mathrm{GAE} / \mathrm{mL}$, in relatively good agreement with those observed by Lugasi and Hovari (909-1228 $\mu \mathrm{g} \mathrm{GAE} / \mathrm{mL})$ [35], Auger et al. (1421 $\pm 222 \mu \mathrm{g}$ GAE/mL) [34], and Tabart et al. $(1530 \pm 453 \mu \mathrm{g} \mathrm{GAE} / \mathrm{mL})$ [18]. Jakobek et al. [36] mention a higher TPC-J $(2770 \pm 64 \mu \mathrm{g} \mathrm{GAE} / \mathrm{mL})$, but for a blackcurrant juice freshly prepared with a juice extractor. Rechner et al. [37] measured a TPC-J of $3627 \mu \mathrm{g}$ GAE/mL, but this concerned a concentrated blackcurrant juice, while commercial juices are diluted to around 30\% (GlaxoSmithKline, Coleford, UK). All these differences in juice TPCs can be explained by the type of fruit or vegetable, the culture mode, and especially the processing method (milling, pressing, pasteurization, filtration, clarification, concentration), which causes more or less degradation.

Regarding polyphenol subclasses, we have found molecules of the flavonol family in all the investigated juices, their total concentration being higher than $10 \mu \mathrm{g} / \mathrm{mL}$ in juices 9 (Grape, Materne) and 10 (Pure Grape, Vitamont), 11 (Pomegranate, Biotta), 12 (Blackcurrant, Biotta), and 19 (Pineapple, Carrefour) (Table 2). In their concentrated blackcurrant juice, Rechner et al. [37] report myricetin, quercetin, and kaempferol concentrations of $24.9,5.54$, and $1 \mu \mathrm{g} / \mathrm{mL}$, respectively, in agreement with our values for the last two compounds in the seven selected blackcurrant juices. We have also detected flavanols in all the tested juices, the total flavanol content being as high as $1194 \mu \mathrm{g} / \mathrm{mL}$ in juice 11 (Pomegranate, Biotta) (Table 2). By comparison, Diaz-Mula et al. [38] report a value of only $147 \mu \mathrm{g} / \mathrm{mL}$ in commercial pomegranate juices from the Mollar cultivar. As expected, we have found anthocyanins only in berry juices, with particularly high levels in blackcurrant juices, despite considerable disparity $(54.40$ to $338 \mu \mathrm{g} / \mathrm{mL})$. The mean value $(159 \pm 99 \mu \mathrm{g} / \mathrm{mL})$ found here for blackcurrant juices is in relatively good agreement with those observed by Tabart et al. [18] $(228 \pm 107 \mu \mathrm{g} / \mathrm{mL})$. Mattila et al. [39] found a 14-fold variation in the anthocyanin content of the 12 analysed European commercial blackcurrant juice products from $17.2 \mu \mathrm{g} / \mathrm{mL}$ (United Kingdom) to $232 \mu \mathrm{g} / \mathrm{mL}$ (Germany) expressed on a ready-to-drink beverage basis. Jacobek at al [36] mention a value of $1543 \pm 5.5 \mu \mathrm{g} / \mathrm{mL}$ in their fresh preparation, while Rechner at al [37] report a total anthocyanin content of $3118 \mu \mathrm{g} / \mathrm{mL}$ in their concentrated blackcurrant juice. Generally speaking, compounds of the flavonol, flavanol, and anthocyanin families represent respectively $0.7,12$, and $11-14.3 \%$ of the TPC-J. By comparison, total anthocyanins represented 55\% of the TPC of the blackcurrant juice prepared with a domestic extractor and $86 \%$ of the TPC of the blackcurrant juice concentrate.

Only a few studies have examined in detail the relationship between the TPC-J and the phenolic profiles of vegetable and fruit juices and/or their potential effects ex vivo on endothelial function. To our knowledge, the most advanced paper in this field was produced by Auger et al. [34], who tested 51 
commercial fruit juices and found only berry products characterized by a red-blue color (blackcurrant, grape, blueberry, cranberry, aronia) to induce marked endothelium-dependent vasorelaxation of isolated pig coronary arteries. These authors concluded, but did not formally prove, that the vasorelaxant effect of juices ( $\mathrm{E}^{+}$at volume ratio $1 \%$ ) depends on their polyphenol composition rather than on their total polyphenol content. In a previous study [18], we confirmed in the same animal model the absence of correlation between the TPC-J and the capacity of blackcurrant juices to induce vasorelaxation. In our rat aorta model (Table 3), we have observed no correlation between $\mathrm{E}^{+}$and TPC-J at the volume ratio used by Auger et al. [34]. At volume ratios 5\% and 10\%, in contrast, we have evidenced significant correlations: $0.58(p=0.04)$ and $0.55(p=0.007)$, respectively. The results in Table 3 lead to similar conclusions regarding the TPC-OB, use of this value being a more realistic approach.

Several previously published studies by our group as well as by others on the effect of polyphenol-rich products on the vascular system have indicated that they can induce endothelium-dependent relaxations in isolated arteries, and vasodilatation in vivo in several experimental models and in humans mainly due to the activation of both NO and endothelium-dependent hyperpolarization (EDH) pathways. Further characterization of the transduction pathways indicated that the activation of the NO pathway in response to polyphenol-rich products (red wine extract, blackcurrant, aronia, green tea, etc.) is due, at least in part, to the redox-sensitive activation of the Src/Akt/PI3-kinase pathway [23].Regarding the endothelium-independent relaxations, natural products have been shown to induce endothelium-dependent relaxations through several mechanisms including interaction with the calcium signaling pathway and an activation of the cyclic AMP and cyclic GMP relaxing pathways, in part, due to phosphodiesterase (PDEs) inhibition [40].

In our study of 22 vegetable and fruit juices, we confirm very contrasting ex vivo vasorelaxant effects between juice categories and even between juices of the same category (Table 2). In our model, the vasorelaxant activities of vegetable and citrus juices (Lemon, Bonneterre) do not appear endothelium dependent, as evidenced by similar $\mathrm{E}^{+}$and $\mathrm{E}^{-}$values at all volume ratios. In contrast, and in accordance with previous findings of ours [18], we find blackcurrant juices, known for their high polyphenol content, to induce substantial vasorelaxation at volume ratio $1 \%$, in the presence but not in the absence of endothelium (exceptions: juices 13 and 14). Yet this observation appears to be influenced by the experimental conditions, since at volume ratio $10 \%$, vasorelaxation percentages could reach $100 \%$ whether endothelium was present or not.

Of great interest is the question: among the phenolic compounds present in vegetable and fruit juices, which are the ones that favor vasorelaxation? The data in Table 3 reveal no correlation, at any volume ratio, between $\mathrm{E}^{+}$and total flavonols or flavanols (mass concentrations) in the OB. At ratio $1 \%$, however, strong correlations appear between $\mathrm{E}+$ and OB concentrations of kaempferol $(r=0.56$, $p=0.009)$ and EGCG $(r=0.41, p=0.05)$. This was particularly surprising for kaempferol, given its presence in very small amount $(0.1-1.2 \mu \mathrm{g} / \mathrm{mL}$ ) in all the tested juices (Table 1). Total anthocyanins in $\mathrm{OB}$, particularly those of blackcurrant juices, correlated strongly $(r=0.75, p=0.05)$ with $\mathrm{E}^{+}$at volume ratio $10 \%$. Amounts of $\mathrm{DG}, \mathrm{DR}$, and $\mathrm{CyR}$ also correlated with $\mathrm{E}^{+}$at this volume ratio. $\mathrm{MG}$ and especially PG $(r=0.96, P=0.00001)$ correlated strongly with $\mathrm{E}^{+}$, but at volume ratio $5 \%$. At volume ratio $1 \%$ we found no correlation. This last observation on our rat model contrasts with our previous findings on porcine artery rings [18]. In the latter case, the potency of blackcurrant juices to induce vasorelaxation at volume ratio $1 \%$ correlated significantly with their total anthocyanin content and with their DG, DR, CyR, and MG contents. Such differences in vascular reactivity according to the volume ratio might also be related to human data indicating that flavonoid bioactivity, as reflected by in vivo endothelial function, does not follow a classical linear dose-response curve [41]. It is also possible that the rat aorta and porcine coronary artery differ markedly as regards their vascular reactivity.

What is the in vivo relevance of ex vivo data on vasorelaxation induced by phenolic compounds present in vegetable and fruit juices? This is an important question. Papers describing consistent data related to vasorelaxation induced by pure compounds are scarce. Mahobiya et al. [42] found 
kaempferol to induce concentration-dependent relaxation in rat pulmonary artery rings pre-contracted with phenylephrine, when present at $0.01 \mu \mathrm{M}$ ( $0 \%$ vasorelaxation) to $10 \mu \mathrm{M}$ (100\% vasorelaxation). $\mathrm{Xu}$ et al. [43] likewise evidenced that kaempferol at $3 \mu \mathrm{M}$ can significantly enhance bradykinin-induced relaxation of porcine coronary artery rings, through both endothelium-derived NO production and endothelium-dependent hyperpolarization. Aggio et al. [44] report $13 \%$ to $50 \%$ vasorelaxation of rat aorta in response to 1 to $100 \mu \mathrm{M}$ EGCG. Thilavech et al. [45] report that $25 \mu \mathrm{M}$ cyanidin-3-O-rutinoside $(\mathrm{CyR})$ can induce $50 \%$ vasorelaxation of rat aorta. In vivo, investigators found plasma concentrations of phenolic compounds to be very low in fasted volunteers, notably because of low bioavailability. When compared to a baseline diet, human plasma quercetin concentration increased form $0.078 \mu \mathrm{M}$ up to $0.304 \mu \mathrm{M}$ after consumption of $110 \mathrm{mg} /$ day flavonol diet during 14 days. [46]. Manach et al. [16] showed the human plasma $C$ concentration to range between 0.14 and $0.49 \mu \mathrm{M}$ after ingestion of $0.36 \mathrm{mg} / \mathrm{kg}$ pure C. Giordano et al. [47] report a plasma cyanidin-3-O-glucoside (CyG) level reaching $0.0040 \mu \mathrm{M} 1 \mathrm{~h}$ after ingestion of $500 \mathrm{~mL}$ orange juice containing $12.89 \mathrm{mg}$ CyG. Liu et al. [48] likewise found the plasma concentration of cyanidin-3-O-galactoside to peak at $0.0031 \mu \mathrm{M}$ around $2 \mathrm{~h}$ after ingestion of $100 \mathrm{~g}$ Saskatoon berries containing $123.5 \mathrm{mg}$ of this compound. Rechner et al. [37] observed peak plasma concentrations of delphinidin-3-O-glucoside $(0.006 \mu \mathrm{M})$, delphinidin-3-O-rutinoside $(0.051 \mu \mathrm{M})$, cyanidin-3-O-glucoside $(0.0035 \mu \mathrm{M})$, and cyanidin-3-O-rutinoside $(0.024 \mu \mathrm{M})$ about $1 \mathrm{~h}$ after ingestion of $330 \mathrm{~mL}$ blackcurrant juice concentrate containing $1 \mathrm{~g}$ total anthocyanins. At least, Kay et al. [49] reported that intake of $20 \mathrm{~g}$ chokeberry extract containing cyanidin-3-glycosides as high as $1.3 \mathrm{~g}$ resulted in an average peak plasma concentration in total anthocyanins and anthocyanins metabolites of $5.1 \mu \mathrm{M}$ within $2 \mathrm{~h}$ post-consumption.

After conversion of mass concentrations to molarities (Table 4), our in vitro study shows that the quercetin concentration $(0.07$ to $0.66 \mu \mathrm{M})$ able to induce vaso-relaxation in OBS at the three $\mathrm{V}_{\text {juice }} / \mathrm{V}_{\mathrm{OBS}}$ ratios was in the physiological range according to data above. Unfortunately, any correlation was found between its concentration in OBS and $\mathrm{E}^{+}$(Table 3). This was not the case for kaempferol whose concentration was close to or less than $0.1 \mu \mathrm{M}$ in the vasorelaxation-inducing organ bath and significantly correlated with the $\mathrm{E}^{+}$(Table 3 ). With respect to the flavanol family, all compounds exhibited at $\mathrm{V}_{\text {juice }} / \mathrm{V}_{\mathrm{OBS}} 1 \%$ vasorelaxant activity below $1 \mu \mathrm{M}$ concentration in agreement with in vivo data of Manach [16]. However, only EGCG concentration correlated with $\mathrm{E}^{+}$at $\mathrm{V}_{\text {juice }} / \mathrm{V}_{\mathrm{OBS}}$ $1 \%$ and $5 \%$ (Table 3). Concentrations of DG, DR and CyR from the anthocyanin family correlated with $\mathrm{E}^{+}$but at a level largely higher than those found in plasma. Of interest was the very strong and significant correlation $(r=0.96, p<0.00001)$ found between PG at a concentration as low as $0.04 \mu \mathrm{M}$ in OBS and $\mathrm{E}^{+}$at $\mathrm{V}_{\text {juice }} / \mathrm{V}_{\mathrm{OBS}} 5 \%$.

Our study highlights some phenolic compounds (kaempferol, EGCG, DG, DR, CyR and PG) in relation to others as to their potential capacity to induce vascular activity. However, concentrations of DR, CyG and in a less extent of PG required for inducing ex vivo vasorelaxation remain, although largely higher than those detected in plasma. Such a difference might be explained, at least in part, by the fact that the bioavailability of phenolic compounds is often assessed in protein free-plasma, and, hence, is unable to detect natural molecules carried by proteins in blood and/or at the cell membrane. Hence, it might not be relevant to compare our data with plasma values since we have observed in preliminary experiments on rats that anthocyanins can rapidly accumulate into endothelial cells and, hence, most likely can reach much higher levels in intracellular cell compartments than in plasma. However, we also have to keep in mind the important hormetic effect of polyphenols, since they are able, at low concentrations, to stimulate the antioxydant Keap1/Nrf2/ARE system (including e-NOS) through moderate production of ROS [8,50]. Whatever the mechanism, endothelium-dependent vasodilation in both experimental models and humans has been observed after the intake of anthocyanin-rich fruit juices, indicating the ability of natural products to reach the endothelium [23]. Recently, we have shown that the intake of $400 \mathrm{~mL}$ of blackcurrant juice Biotta (juice 12) containing $536 \mathrm{mg}$ of polyphenols (including $21.76 \mathrm{mg}$ of total anthocyanins) resulted $1 \mathrm{~h}$ after ingestion in a significant increase (35.8\%) of human endothelial function as evaluated by measurement of the Reactive Hyperemia Index (RIH) [51]. 


\section{Conclusions}

As pertinently noted by Habauzit and Morand [15], only a few publications report in vitro studies using polyphenols at concentrations $(\mu \mathrm{M})$ nutritionally achievable in aglycone or conjugated form after consumption of polyphenol-containing foods. In the present paper, we have tried to show how to adequately manage and interpret information about vasorelaxation effects induced by vegetable and fruit juices under ex-vivo experimental conditions. In addition to determining TPC-J values, our first step was to assay total subclass (anthocyanins, flavanols, flavonols) and individual levels of polyphenols in the juices studied. High priority was also given to analyzing relationships between vasorelaxant intensity and total and individual phenolic compound concentrations in the organ baths rather than the juices. This enabled us to highlight that kaempferol, EGCG and peonidin-3-O-glucoside (PG) present in fruit juices, and more particularly the blackcurrant ones, might have some in vivo relevance, as their $\mathrm{OB}$ concentrations were compatible with physiological levels and correlated strongly and significantly with the E+. Yet great caution is required in interpreting data which seem to depend on experimental conditions. A simple example is the non-correlation between TPC-J or TPC-OB and vasorelaxant intensity at $\mathrm{V}_{\text {juice }} / \mathrm{V}_{\mathrm{OBS}}$ ratio $1 \%$, in contrast to the correlations observed at $5 \%$ or $10 \%$.

Even if endothelium-dependent vasodilation in both experimental models and humans have been reported after the intake of anthocyanin-rich fruit juices [23], large-scale clinical studies are needed to further and better explore in humans the beneficial endothelium-dependent cardiovascular effects of vegetable and fruit juice intake [52] and hence of polyphenols present in these foods [41]. This requires evaluating in vivo endothelial function in three with the measurement of plasma concentrations of both polyphenol metabolites by HPLC-MS/MS [48] and NO. On the basis of results from such an effective battery of tests, the European Food Safety Authority has authorized, under article 13(5) of Regulation (EC) No 1924/2006, a health claim related to cocoa flavanols and maintenance of normal endothelium-dependent vasodilation. By contrast, the PRISMA-compliant meta-analysis recently performed by Zhu et al. [53] does not favor any blood pressure-improving clinical efficacy of anthocyanin supplementation.

Author Contributions: J.D. welcomed to his laboratory A.M., from Quevedo University, Equador, in the context of work towards a PhD in Biochemistry and Molecular Biology from the University of Liège, Belgium. A.M., J.T., C.K., and J.P. were the main investigators and contributors to drafting the present manuscript. They decided together to submit the paper for publication in Antioxidants, with the agreement of all the other authors. Comments of colleagues C.A. and V.S.-K. of Strasbourg University, France helped with manuscript corrections. J.-O.D. submitted the notice protocol to the local animal ethics committee. B.P. provided access to all the necessary materials for evaluating the vasorelaxant effects of juices on isolated segments of rat aorta. J.-P.C.-B. greatly contributed to the good running of animal experiments. All authors have read and agreed to the published version of the manuscript.

Funding: This research received no external funding.

Acknowledgments: The authors greatly thank Kathleen Broman for the correction of English.

Conflicts of Interest: The authors declare no conflict of interest.

\section{References}

1. Casas, R.; Castro-Barquero, S.; Estruch, R.; Sacanella, E. Nutrition and Cardiovascular Health; MDPI: Basel, Switzerland, 2018; Volume 19, ISBN 3493227574.

2. Fraga, C.G.; Croft, K.D.; Kennedy, D.O.; Tomás-Barberán, F.A. The effects of polyphenols and other bioactives on human health. Food Funct. 2019, 10, 514-528. [CrossRef] [PubMed]

3. Rodríguez-García, C.; Sánchez-Quesada, C.; Gaforio, J.J. Dietary flavonoids as cancer chemopreventive agents: An updated review of human studies. Antioxidants 2019, 8, 137. [CrossRef] [PubMed]

4. Bungau, S.; Abdel-Daim, M.M.; Tit, D.M.; Ghanem, E.; Sato, S.; Maruyama-Inoue, M.; Yamane, S.; Kadonosono, K. Health benefits of polyphenols and carotenoids in age-related eye diseases. Oxid. Med. Cell. Longev. 2019. [CrossRef] [PubMed] 
5. Potì, F.; Santi, D.; Spaggiari, G.; Zimetti, F.; Zanotti, I. Polyphenol health effects on cardiovascular and neurodegenerative disorders: A review and meta-analysis. Int. J. Mol. Sci. 2019, 20, 351. [CrossRef] [PubMed]

6. Hertog, M.G.; Feskens, E.J.; Hollman, P.C.; Katan, M.B.; Kromhout, D. Dietary antioxidant flavonoids and risk of coronary heart disease: The zutphen aledery sudy. Lancet 1993, 34, 1007-1011. [CrossRef]

7. Mendonça, R.D.; Carvalho, N.C.; Martin-Moreno, J.M.; Pimenta, A.M.; Lopes, A.C.S.; Gea, A.; Martinez-Gonzalez, M.A.; Bes-Rastrollo, M. Total polyphenol intake, polyphenol subtypes and incidence of cardiovascular disease: The SUN cohort study. Nutr. Metab. Cardiovasc. Dis. 2019, 29, 69-78. [CrossRef]

8. Zhou, Y.; Jiang, Z.; Lu, H.; Xu, Z.; Tong, R.; Shi, J.; Jia, G. Recent Advances of Natural Polyphenols Activators for Keap1-Nrf2 Signaling Pathway. Chem. Biodivers. 2019. [CrossRef]

9. Schini-Kerth, V.B.; Étienne-Selloum, N.; Chataigneau, T.; Auger, C. Vascular protection by natural product-derived polyphenols: In vitro and in vivo evidence. Planta Med. 2011, 77, 1161-1167. [CrossRef]

10. Yamagata, K. Polyphenols regulate endothelial functions and reduce the risk of cardiovascular disease. Curr. Pharm. Des. 2019. [CrossRef]

11. Messner, B.; Bernhard, D. Smoking and cardiovascular disease: Mechanisms of endothelial dysfunction and early atherogenesis. Arterioscler. Thromb. Vasc. Biol. 2014, 34, 509-515. [CrossRef]

12. Incalza, M.A.; D'Oria, R.; Natalicchio, A.; Perrini, S.; Laviola, L.; Giorgino, F. Oxidative stress and reactive oxygen species in endothelial dysfunction associated with cardiovascular and metabolic diseases. Vasc. Pharm. 2018, 100, 1-19. [CrossRef] [PubMed]

13. Haybar, H.; Shahrabi, S.; Rezaeeyan, H.; Shirzad, R.; Saki, N. Endothelial cells: From dysfunction mechanism to pharmacological effect in cardiovascular disease. Cardiovasc. Toxicol. 2019, 19, 13-22. [CrossRef] [PubMed]

14. Schwingshackl, L.; Hoffmann, G. Mediterranean dietary pattern, inflammation and endothelial function: A systematic review and meta-analysis of intervention trials. Nutr. Metab. Cardiovasc. Dis. 2014, 24, 929-939. [CrossRef] [PubMed]

15. Habauzit, V.; Morand, C. Evidence for a protective effect of polyphenols-containing foods on cardiovascular health: An update for clinicians. Ther. Adv. Chronic Dis. 2012, 3, 87-106. [CrossRef] [PubMed]

16. Manach, C.; Williamson, G.; Morand, C.; Scalbert, A.; Rémésy, C. Bioavailability and bioefficacy of polyphenols in humans. I. Review of 97 bioavailability studies. Am. J. Clin. Nutr. 2005, 81, 230-242. [CrossRef]

17. Mihalache Arion, C.; Tabart, J.; Kevers, C.; Niculaua, M.; Filimon, R.; Beceanu, D.; Dommes, J. Antioxidant potential of different plum cultivars during storage. Food Chem. 2014, 146, 485-491. [CrossRef]

18. Tabart, J.; Auger, C.; Kevers, C.; Dommes, J.; Pollet, B.; Defraigne, J.O.; Schini-Kerth, V.B.; Pincemail, J. The potency of commercial blackcurrant juices to induce relaxation in porcine coronary artery rings is not correlated to their antioxidant capacity but to their anthocyanin content. Nutrition 2018, 51-52, 53-59. [CrossRef]

19. Liu, R.H. Heath-promoting components of fruits and vegetables in the diet. Adv. Nutr. 2013, 4, 384S-392S. [CrossRef]

20. Wang, X.; Ouyang, Y.; Liu, J.; Zhu, M.; Zhao, G.; Bao, W.; Hu, F.B. Fruit and vegetable consumption and mortality from all causes, cardiovascular disease, and cancer: Systematic review and dose-response meta-analysis of prospective cohort studies. BMJ 2014, 349, 1-14. [CrossRef]

21. Alissa, E.M.; Ferns, G.A. Dietary fruits and vegetables and cardiovascular diseases risk. Crit. Rev. Food Sci. Nutr. 2017, 57, 1950-1962. [CrossRef]

22. Angelino, D.; Godos, J.; Ghelfi, F.; Tieri, M.; Titta, L.; Lafranconi, A.; Marventano, S.; Alonzo, E.; Gambera, A.; Sciacca, S.; et al. Fruit and vegetable consumption and health outcomes: An umbrella review of observational studies. Int. J. Food Sci. Nutr. 2019, 70, 652-667. [CrossRef] [PubMed]

23. Oak, M.H.; Auger, C.; Belcastro, E.; Park, S.H.; Lee, H.H.; Schini-Kerth, V.B. Potential mechanisms underlying cardiovascular protection by polyphenols: Role of the endothelium. Free Radic. Biol. Med. 2018, 122, 161-170. [CrossRef] [PubMed]

24. Ruxton, C.H.S.; Gardner, E.J.; Walker, D. Can pure fruit and vegetable juices protect against cancer and cardiovascular disease too? A review of the evidence. Int. J. Food Sci. Nutr. 2006, 57, 249-272. [CrossRef]

25. Hyson, D.A. A review andc ritical analysis of the scientific literature related to $100 \%$ fruit juice and human health. Adv. Nutr. 2015, 6, 37-51. [CrossRef] [PubMed] 
26. Khan, F.; Ray, S.; Craigie, A.M.; Kennedy, G.; Hill, A.; Barton, K.L.; Broughton, J.; Belch, J.J.F. Lowering of oxidative stress improves endothelial function in healthy subjects with habitually low intake of fruit and vegetables: A randomized controlled trial of antioxidant- and polyphenol-rich blackcurrant juice. Free Radic. Biol. Med. 2014, 72, 232-237. [CrossRef] [PubMed]

27. Tzulker, R.; Glazer, I.; Bar-Ilan, I.; Holland, D.; Aviram, M.; Amir, R. Antioxidant activity, polyphenol content, and related compounds in different fruit juices and homogenates prepared from 29 different pomegranate accessions. J. Agric. Food Chem. 2007, 55, 9559-9570. [CrossRef] [PubMed]

28. Borges, G.; Mullen, W.; Crozier, A. Comparison of the polyphenolic composition and antioxidant activity of European commercial fruit juices. Food Funct. 2010, 1, 73-83. [CrossRef] [PubMed]

29. Nowak, D.; Gośliński, M.; Szwengiel, A. Multidimensional comparative analysis of phenolic compounds in organic juices with high antioxidant capacity. J. Sci. Food Agric. 2017, 97, 2657-2663. [CrossRef]

30. Granato, D.; Karnopp, A.R.; van Ruth, S.M. Characterization and comparison of phenolic composition, antioxidant capacity and instrumental taste profile of juices from different botanical origins. J. Sci. Food Agric. 2015, 95, 1997-2006. [CrossRef]

31. Wern, K.H.; Haron, H.H.; Keng, C.B. Comparison of total phenolic contents (TPC) and antioxidant activities of fresh fruit juices, commercial $100 \%$ fruit juices and fruit drinks. Sains Malays. 2016, 45, 1319-1327.

32. Mena, P.; Vegara, S.; Martí, N.; García-Viguera, C.; Saura, D.; Valero, M. Changes on indigenous microbiota, colour, bioactive compounds and antioxidant activity of pasteurised pomegranate juice. Food Chem. 2013, 141, 2122-2129. [CrossRef] [PubMed]

33. Li, X.; Wasila, H.; Liu, L.; Yuan, T.; Gao, Z.; Zhao, B.; Ahmad, I. Physicochemical characteristics, polyphenol compositions and antioxidant potential of pomegranate juices from 10 Chinese cultivars and the environmental factors analysis. Food Chem. 2015, 175, 575-584. [CrossRef] [PubMed]

34. Auger, C.; Pollet, B.; Arnold, C.; Marx, C.; Schini-Kerth, V.B. Great heterogeneity of commercial fruit juices to induce endothelium-dependent relaxations in isolated porcine Coronary Arteries: Role of the phenolic content and composition. J. Med. Food 2015, 18, 128-136. [CrossRef] [PubMed]

35. Lugasi, A.; Hóvári, J. Antioxidant properties of commercial alcoholic and nonalcoholic beverages. Nahrung 2003, 47, 79-86. [CrossRef]

36. Jakobek, L.; Seruga, M.; Medvidovic-Kosanovic, M.; Novak, I. Anthocyanin content and antioxidant activity of various red fruit juices. Dtsch. Lebensm. 2007, 103, 58-64.

37. Rechner, A.R.; Kuhnle, G.; Hu, H.; Roedig-Penman, A.; van den Braak, M.H.; Moore, K.P.; Rice-Evans, C.A. The metabolism of dietary polyphenols and the relevance to circulating levels of conjugated metabolites. Free Radic. Res. 2002, 36, 1229-1241. [CrossRef]

38. Díaz-Mula, H.M.; Tomás-Barberán, F.A.; García-Villalba, R. Pomegranate fruit and juice (cv. Mollar), rich in ellagitannins and anthocyanins, also provide a significant content of a wide range of proanthocyanidins. J. Agric. Food Chem. 2019, 67, 9160-9167. [CrossRef]

39. Mattila, P.H.; Hellström, J.; McDougall, G.; Dobson, G.; Pihlava, J.M.; Tiirikka, T.; Stewart, D.; Karjalainen, R. Polyphenol and vitamin C contents in European commercial blackcurrant juice products. Food Chem. 2011, 127, 1216-1223. [CrossRef]

40. Alamgeer, A.; Auger, C.; Chabert, P.; Lugnier, C.; Mushtaq, M.N.; Schini-Kerth, V.B. Mechanisms underlying vasorelaxation induced in the porcine coronary arteries by Thymus linearis, Benth. J. Ethnopharmacol. 2018, 225, 211-219. [CrossRef]

41. Kay, C.D.; Hooper, L.; Kroon, P.A.; Rimm, E.B.; Cassidy, A. Relative impact of flavonoid composition, dose and structure on vascular function: A systematic review of randomized controlled trials of flavonoid-rich food products. Mol. Nutr. Food Res. 2012, 56, 1605-1616. [CrossRef]

42. Mahobiya, A.; Singh, T.U.; Rungsung, S.; Kumar, T.; Chandrasekaran, G.; Parida, S.; Kumar, D. Kaempferol-induces vasorelaxation via endothelium-independent pathways in rat isolated pulmonary artery. Pharmacol. Rep. 2018, 70, 863-874. [CrossRef] [PubMed]

43. Xu, Y.C.; Leung, S.W.S.; Leung, G.P.H.; Man, R.Y.K. Kaempferol enhances endothelium-dependent relaxation in the porcine coronary artery through activation of large-conductance $\mathrm{Ca}^{2+}$-activated $\mathrm{K}^{+}$channels. $\mathrm{Br}$. J. Pharmacol. 2015, 172, 3003-3014. [CrossRef] [PubMed]

44. Aggio, A.; Grassi, D.; Onori, E.; D’Alessandro, A.; Masedu, F.; Valenti, M.; Ferri, C. Endothelium/nitric oxide mechanism mediates vasorelaxation and counteracts vasoconstriction induced by low concentration of flavanols. Eur. J. Nutr. 2013, 52, 263-272. [CrossRef] [PubMed] 
45. Thilavech, T.; Abeywardena, M.Y.; Adams, M.; Dallimore, J.; Adisakwattana, S. Naturally occurring anthocyanin cyanidin-3-rutinoside possesses inherent vasorelaxant actions and prevents methylglyoxal-induced vascular dysfunction in rat aorta and mesenteric arterial bed. Biomed. Pharmacother. 2017, 95, 1251-1259. [CrossRef] [PubMed]

46. Noroozi, M.; Burns, J.; Crozier, A.; Kelly, I.E.; Lean, M.E.J. Prediction of dietary flavonol consumption from fasting plasma concentration or urinary excretion. Eur. J. Clin. Nutr. 2000, 54, 143-149. [CrossRef] [PubMed]

47. Giordano, L.; Coletta, W.; Rapisarda, P.; Donati, M.B.; Rotilio, D. Development and validation of an LC-MS/MS analysis for simultaneous determination of delphinidin-3-glucoside, cyanidin-3-glucoside and cyanidin-3-(6-malonylglucoside) in human plasma and urine after blood orange juice administration. J. Sep. Sci. 2007, 30, 3127-3136. [CrossRef] [PubMed]

48. Liu, J.; Song, J.; Huang, K.; Michel, D.; Fang, J. HPLC-MS/MS analysis of anthocyanins in human plasma and urine using protein precipitation and dilute-and-shoot sample preparation methods, respectively. Biomed. Chromatogr. 2018, 32, 1-8. [CrossRef]

49. Kay, D.J.; Mazza, G.; Holub, B.J.; Wang, J. Anthocyanin metabolites in human urine and serum. Br. J. Nutr. 2004, 91, 933-942. [CrossRef]

50. Birringer, M. Hormetics: Dietary triggers of an adpatative stress response. Pharm. Res. 2011, 28, $2680-2694$. [CrossRef]

51. Pincemail, J.; Defraigne, J.O.; Courtois, A.; Albert, A.; Cheramy-Bien, J.P.; Sakalihasan, N. Abdominal Aortic Aneurysm (AAA): Is There a Role for the Prevention and Therapy Using Antioxidants? Curr. Drug Targets 2018, 19, 1256-1264. [CrossRef]

52. Ray, S.; Miglio, T.B.; Del Rio, D. Assessment of vascular and endothelial dysfunction in nutritional studies. Nutr. Metab. Cardiovasc. Dis. 2014, 24, 940-946. [CrossRef] [PubMed]

53. Zhu, Y.; Bao, Y.; Wang, X.; Lu, W.; Wang, X.; Han, Z.; Qiu, C. The effect of anthocyanins on blood pressure. A PRISMA-compliant meta-analysis of randomized clinical trials. Medicine 2016, 95, 1-7.

(C) 2020 by the authors. Licensee MDPI, Basel, Switzerland. This article is an open access article distributed under the terms and conditions of the Creative Commons Attribution (CC BY) license (http://creativecommons.org/licenses/by/4.0/). 